\title{
A CANDIDATURA DE PASTOR EVERALDO NAS ELEIÇÕES PRESIDENCIAIS DE 2014 E AS METAMORFOSES DO DISCURSO POLÍTICO EVANGÉLICO
}

\author{
Rafael Bruno Gonçalves ${ }^{1}$
}

\begin{abstract}
Resumo: A inserção dos evangélicos na política brasileira é cada vez mais constante. Sobre este ponto, o artigo pretende trazer uma breve contribuição a respeito da experiência histórica da participação deste segmento religioso no campo político, a trajetória do Partido Social Cristão (PSC) e o desempenho da candidatura majoritária de Pastor Everaldo nas eleições presidenciais de 2014, através da análise discursiva dos posicionamentos do candidato durante a campanha eleitoral. Pretende-se demonstrar o surgimento de um novo perfil de candidatura evangélica, que explora não somente um tipo de conservadorismo moral, mas também socioeconômico. Ao mesmo tempo, a candidatura de Pastor Everaldo inova no momento em que passa a representar uma nova alternativa para o eleitor evangélico, visto que o candidato se apresentou enquanto representante deste segmento religioso. Dessa forma, a candidatura do PSC poderá contribuir para uma melhor visualização do eleitor evangélico, que não esteve concentrado apenas em partidos como PT, PSDB e PSB durante o primeiro turno das eleições presidenciais de 2014. Todas as propagandas do PSC apresentadas no Horário Gratuito de Propaganda Eleitoral (HGPE) foram submetidas à análise do discurso.
\end{abstract}

Palavras-chave: Evangélicos; Eleiçóes 2014; Discurso; Conservadorismo.

Abstract: The insertion of evangelicals in Brazilian politics is becoming more constant. On this point, the paper presents a brief contribution on the historical experience of participation in religious segment in the political field, the trajectory of the Social Christian Party (PSC) and the performance of the majority candidate Pastor Everaldo in the presidential elections in 2014 by discoursive analysis of the

1 Doutorando em Sociologia pelo Instituto de Estudos Sociais e Políticos da Universidade do Estado do Rio de Janeiro (IESP-UERJ). Bolsista da Fundação Carlos Chagas Fundo de Amparo à Pesquisa do Estado do Rio de Janeiro (FAPERJ). Contato: rafaelgoncalves @iesp.uerj.br

Debates do NER, Porto Alegre, ano I6, N. 27, P. 323-348, JAn./Jun. 2015 
candidate's positions during the election campaign. It aims to demonstrate the emergence of a new evangelical candidacy profile, which explores not only a kind of moral conservatism, but also socioeconomic. At the same time, the candidate Pastor Everaldo innovates the moment it comes to represent a new alternative for evangelical voters, as the candidate presented himself as a representative of this religious segment. Thus, the PSC candidate could contribute to a better view of evangelical voters, who were not concentrated only in parties such as PT, PSDB and PSB during the first round of the presidential elections of 2014. All PSC propaganda displayed on Free Electoral Propaganda Time (HGPE) were submitted to discourse analysis.

Keywords: Evangelicals; 2014 elections; Discourse; Conservatism.

\section{INTRODUÇÃO}

As eleições presidenciais de 2014 evidenciaram um cenário diferenciado no que diz respeito à seleção de algumas candidaturas. Entre os candidatos, rapidamente destacou-se o nome de Pastor Everaldo, pelo Partido Social Cristão (PSC), para Presidente da República. Everaldo Dias Pereira foi o primeiro candidato ao cargo que explorou no nome para a urna a sua orientação religiosa, utilizando a palavra "pastor". No entanto, deve-se ressaltar a ocorrência de outras candidaturas presidenciais que também exploravam a orientação religiosa nos processos eleitorais anteriores. $\mathrm{Na}$ campanha presidencial de 1989, surgiram os primeiros boatos de uma candidatura evangélica pelo PMDB, através do nome de Íris Rezende, membro da Igreja Cristã Evangélica. Rezende foi ministro da Agricultura durante o governo de José Sarney. Antes da convenção do PMDB, o pré-candidato recebeu o apoio de centenas de lideranças evangélicas, principalmente da Assembleia de Deus. Em abril de 1989, sua candidatura foi derrotada, sendo escolhido como candidato o presidente do PMDB, Ulysses Guimarães (Mariano; Pierucci, 1992). Sem uma candidatura evangélica, durante a campanha eleitoral em 1989, os evangélicos resolveram apoiar Fernando Collor, do Partido da Reconstrução Nacional (PRN).

Debates do NER, Porto Alegre, ANo I6, N. 27, P. 323-348, JAN./Jun. 2015 
Foi somente na eleição de 2002 que surgiu uma candidatura legítima do segmento evangélico. Anthony Garotinho, candidato pelo Partido Socialista Brasileiro (PSB), havia se convertido ao protestantismo logo após sofrer um acidente de automóvel. A Igreja Universal do Reino de Deus declarou apoio ao candidato no primeiro turno, assim como alguns membros da Assembleia de Deus e da Igreja Sara Nossa Terra (Campos, 2006).

A eleição presidencial de 2010 teve como principal representante dos evangélicos a candidata Marina Silva, do Partido Verde (PV). Marina saiu do PT em 2009 e é reconhecida por suas lutas envolvendo questôes relacionadas ao meio ambiente. Filiada à Igreja Assembleia de Deus, Marina também recebeu o apoio de outras denominações evangélicas na corrida presidencial.

Em comparação com os processos eleitorais anteriores, em 2014, a eleição presidencial apresentou um quadro diferenciado. Com o nome de Pastor Everaldo como candidato pelo PSC, o segmento religioso parecia ter encontrado um representante capaz de unir as diferentes igrejas evangélicas no Brasil em torno de um único projeto político. Pastor Everaldo é membro da Igreja Assembleia de Deus e atua no ramo empresarial, sendo também vice-presidente nacional do PSC. De família evangélica, Everaldo ingressou na política durante o governo de Anthony Garotinho, no Rio de Janeiro, sendo subsecretário da Casa Civil e um dos responsáveis pela implementação do programa Cheque Cidadão, uma espécie de programa de transferência de renda em que cupons de diferentes valores são repassados para famílias de baixa renda que possuem filhos matriculados em escolas da rede pública de ensino no Rio de Janeiro. O cheque é repassado através de instituições religiosas, geralmente igrejas evangélicas.

Sobre a escolha de Pastor Everaldo enquanto representante do setor evangélico, no decorrer da campanha eleitoral, logo após o acidente aéreo que resultou na morte do candidato presidenciável Eduardo Campos, pelo PSB, surgiu o nome de Marina Silva, vice-candidata na coligação Unidos pelo Brasil (PHS/PRP/PPS/PPL/PSB/PSL), que assumiu o lugar de Eduardo Campos. Diversos agrupamentos evangélicos sinalizaram o

Debates do NER, Porto Alegre, ano I6, N. 27, P. 323-348, JAn./Jun. 2015 
apoio à candidata do PSB, como a Convenção Geral das Assembleias de Deus do Brasil (CGADB), que deixou de apoiar Pastor Everaldo para apoiar Marina Silva.

A candidatura de Everaldo abriu a possibilidade de uma melhor visualização do eleitor evangélico, visto que o voto não estava mais dividido entre os partidos PT, PSDB e PSB. Contudo, Everaldo não conseguiu manter o ritmo de $4 \%$ das intenções de voto, segundo a pesquisa Datafolha de junho de 2014, e contabilizou, no final do processo eleitoral, apenas 0,75\% dos votos válidos. Marina Silva tornou-se a candidata dos evangélicos, como demonstrou a pesquisa de intenção de votos por religião realizada pelo Ibope em agosto de 2014. A candidata chegou aos 37\% entre os eleitores evangélicos contra 4\% dos eleitores de Pastor Everaldo².

No entanto, as mudanças que ocorreram em torno do discurso político do candidato do PSC, por si só, demonstram a importância da análise sobre o tema. Everaldo apostou ao longo da campanha em um discurso que combinava elementos oriundos de um conservadorismo moral e também de ordem econômica. Não é nenhuma novidade que os evangélicos passaram a readequar os seus discursos, deixando de lado o caráter proselitista confessional, para adentrarem na esfera política. No Congresso Nacional, os parlamentares fazem uso de uma retórica cada vez mais ajustada ao que é propriamente discutido no âmbito legislativo, e, em diversas circunstâncias, levam essa retórica para os seus canais de comunicação, como jornais e revistas, e até mesmo para os cultos no púlpito.

As propagandas eleitorais de Everaldo evidenciaram essa mescla em torno dos principais temas que eram apresentados nas inserções. Everaldo, em diversas ocasióes, argumentava que a sua candidatura agia na defesa da vida do ser humano desde a sua concepção, sendo contrário a legalização das drogas e atuando na defesa da família como está na Constituição Brasi-

2 Conforme apontaram as pesquisas eleitorais em 2014, o crescimento expressivo de Marina Silva foi resultante do estado de comoção e fervor nacional provocado pela drástica morte de Eduardo Campos.

Debates do NER, Porto Alegre, Ano i6, N. 27, P. 323-348, JAN./Jun. 2015 
leira, assim como a redução da máquina do Estado ao mínimo necessário, passando tudo o que fosse possível para a iniciativa privada. Percebe-se que os três primeiros temas apresentam uma forte conotação religiosa, porém, o último tema possui um viés relativo à ideologia neoliberal.

\section{OS EVANGÉLICOS NA POLÍTICA BRASILEIRA}

Os evangélicos brasileiros, até o início dos anos 80, apresentavam uma postura de autoexclusão deliberada da participação político-partidária. Poucas foram as ocasiōes em que estes religiosos decidiram entrar na política, que geralmente ocorriam sem a direção e o apoio das lideranças religiosas $^{3}$. Contudo, em meados dos anos 80 , as maiores igrejas pentecostais

3 Existem registros sobre esta presença durante a República Velha, mais precisamente, nos seguintes estados: São Paulo, quando foi eleito prefeito de Lençóis Paulista o presbiteriano Francisco Augusto Pereira; no Mato Grosso, com a eleição do deputado federal batista Luiz Alexandre de Oliveira; no Pará, com o Vice-Governador presbiteriano Antônio Teixeira Gueiros; e no Ceará, com a eleição do Pastor presbiteriano Natanael Cortez. Contudo, foi a partir da Constituinte de 1933-34 que ocorreu a estreia do chamado "político evangélico", através da eleição do paulistano e pastor Metodista Guaracy Silveira para o parlamento, candidato do Partido Socialista, eleito naquele período com mais de mil votos (Campos, 2006). Nas eleições de 1947, houve um crescimento de deputados estaduais e vereadores evangélicos eleitos (Oro, 2006) e, na Câmara Federal, foram eleitos cinco evangélicos durante a 39ª Legislatura (1951-1954). A participação evangélica na Câmara oscilou entre seis e doze parlamentares até a 47a Legislatura (1983-1987). No entanto, em comparação com as legislaturas anteriores, foi a partir da Assembleia Nacional Constituinte que os evangélicos começaram a garantir uma posição de destaque na política, ingressando em maior número e obtendo melhores resultados. A bancada pluripartidária dos evangélicos era composta por 33 membros em 1986. Em 1990, a representação evangélica no Congresso caiu para 22 deputados, porém, em 1994, houve um tímido crescimento para 31 parlamentares. Em 1998, 2002, 2010 e 2014 foram registradas as maiores representações evangélicas na Câmara, respectivamente: 53, 71, 77 e 75 deputados eleitos, com exceção de 2006, período que registrou uma nova queda, com 43 deputados evangélicos eleitos.

Debates do NER, Porto Alegre, ano I6, N. 27, P. 323-348, JAn./Jun. 2015 
e neopentecostais decidiram ingressar na política, rompendo com a postura sectária e isolada de outrora, apresentando candidaturas oficiais das igrejas, de forma organizada, em defesa dos seus interesses corporativos, motivados por valores religiosos (Mariano, 2010). A mobilização de eleitores fiéis evangélicos a partir deste período contou com o lema "irmão vota em irmão". Regina Novaes afirma que foi primeiramente durante os anos 70 e 80 que os pentecostais passaram a atribuir um caráter religioso às categorias políticas e "[...] entraram em lutas sociais 'em nome de Jesus'" (Novaes, 2002, p. 78-79). Porém, para entender o que a religião traz de específico para a política, segundo a autora, deve-se caracterizar ambas como:

[...] dimensões distintas da vida social. Desde o início da modernidade, a religião e a política vieram a conformar espaços sociais diversos, com instituições, finalidades e inserções temporais específicas. Porém, as fronteiras entre tais espaços não são estanques e impermeáveis. O desafio analítico maior está em reconhecer as especializaçōes, historicamente construídas, sem reificar a oposição entre o político e o religioso. Trata-se, antes, de aprender os efeitos da religião sobre a política e vice-versa. [...] a religião não pode ser considerada apenas como uma força política entre outras. É preciso levar em conta o específico simbolismo verbal e ritual que ela encerra, justamente para compreender o peso e o lugar da religião na política. (Novaes, 2002, p. 63).

Entender estes símbolos e signos que são mobilizados pelos parlamentares evangélicos na política representa um passo importante na compreensão da dinâmica discursiva suscitada no campo legislativo em torno de temas que são considerados polêmicos pelos deputados religiosos por conta de seu conteúdo moral. Novaes observa que não existe política sem símbolos, e que os símbolos religiosos não esgotam os seus significados, sendo estes inseridos em diversas questões humanas, além de estarem sempre sendo reutilizados para fins políticos. Muitos daqueles que fazem ou compartilham as opiniōes políticas, levam consigo suas crenças, incertezas e o aparato simbólico que é mobilizador (Novaes, 2002).

Debates do NER, Porto Alegre, ANo I6, N. 27, P. 323-348, JAN./Jun. 2015 
Paul Freston (1993) questionou como lideranças pentecostais, principalmente aquelas vinculadas à denominação pentecostal Assembleia de Deus, decidem mudar o panorama tradicional no qual o discurso muitas vezes utilizado por elas era "crente não se mete em política" (Freston, 1993, p. 180, grifo nosso). O marco desta transformação ocorreu na Assembleia Constituinte, no momento em que lideranças da Assembleia de Deus, receando que a nova Carta Magna colocasse limites na liberdade religiosa dos evangélicos e estabelecesse a Igreja Católica como religião oficial, decidem ingressar na carreira política. A inserção evangélica, a partir de 1986, era identificada principalmente nos partidos conservadores ou fisiológicos e muitos destes deputados apresentavam uma origem social mais baixa. A classe política pentecostal basicamente era representada por comunicadores, familiares de pastores e empresários (Freston, 1993). Durante a Constituinte, o autor identifica as diversas tentativas, principalmente por parte dos protestantes históricos, de aglutinar estes parlamentares evangélicos, mesmo sendo dispersos partidariamente. Como o autor afirma:

As diretrizes eram a unidade em questôes comportamentais, a postura positiva para com o governo e o esvaziamento religioso de questôes como a reforma agrária. A bancada foi logo contestada por uma minoria com outra concepção de política. Posteriormente, surgiu uma liderança pentecostal mais "agressiva" no estilo e menos direitista. (Freston, 1993, p. 282).

Com relação à temática desenvolvida pelo setor evangélico no espaço Legislativo, Freston argumenta que em "[...] termos legislativos, os evangélicos deram ênfase à família, à mídia e ao simbolismo religioso na vida pública. Segundo a nota DIAP, os pentecostais constituíram mais um centro fisiológico do que uma direita ideológica" (Freston, 1993, p. 282), uma conduta que estava concentrada na busca de benefícios para as igrejas, satisfazendo os interesses de cada agremiação religiosa, em detrimento do bem comum. Em suma, Freston chega a uma importante conclusão sobre a questão da crescente participação evangélica na política, mais precisamente sobre o grau de pluralidade dos evangélicos nos espaços políticos de

Debates do NER, Porto Alegre, ano I6, N. 27, P. 323-348, JAn./Jun. 2015 
discussões, dificultando assim a formação de um grupo coeso, mas que também isso pode ser considerado bom para a democracia, pois, segundo Freston:

O protestantismo brasileiro, por mais que cresça, não formará uma neo-cristandade evangélica. O campo evangélico é segmentado por essência; todos os esforços de unificá-los serão contestados. $\mathrm{O}$ fato de que a religião que mais cresce no Brasil e que tem mais ambição política é institucionalmente dividida e opera num formato pluralista é bom para a democracia, quaisquer que sejam as pretensões de alguns líderes. (Freston, 1993, p. 287).

Com o início dos trabalhos na Assembleia Constituinte, em 1987, foi possível identificar o exato momento em que se formou o grupo evangélico parlamentar. Como exercia um papel importante para suas instituições religiosas, esse grupo tornou-se objeto de análise em temas que, em determinadas circunstâncias, demonstravam o caráter conservador de uma parcela relevante dos parlamentares evangélicos eleitos naquele período.

Mudam as legislaturas e, consequentemente, muda, em alguns aspectos, a atuação do segmento evangélico, transformações essas que são perceptíveis também na Câmara Federal. No atual cenário político brasileiro, é preciso considerar a receptividade e também a hostilidade que os evangélicos encontram por parte de parlamentares, partidos e governadores das mais diversas orientações ideológicas. A cultura política nacional, segundo Ricardo Mariano, tem contribuído para reforçar este ativismo político, visto que, a cada eleição, o apoio eleitoral evangélico é disputado pelos candidatos a cargos legislativos e executivos (Mariano, 2010), em que muitos exigem o apoio político em troca de favores corporativos, na concessão de recursos e na formulação e implementação de políticas públicas realizadas em parceira com igrejas. O envolvimento de políticos evangélicos, nos últimos anos, pode ser caracterizado como:

[...] sistematicamente requerido, estimulado, cobrado, barganhado por considerável parte da classe política brasileira, o que tem como efeito imediato

Debates do NER, Porto Alegre, Ano I6, N. 27, P. 323-348, JAN./Jun. 2015 
reforçar, incrementar e legitimar a presença, a participação, a influência, o poder de pressão e de barganha desses religiosos na esfera pública, espaço no qual também atuam intensamente por meio de suas emissoras e redes de rádio e tevê, de jornais, revistas, gravadoras e mercado editorial. (Mariano, 2010, p. 107).

O cenário de análise explorado nesta pesquisa exige a atenção sobre as relações entre Estado e religião, visto que é cada vez mais presente a atitude dos atores políticos religiosos de ressignificação do político, de pluralidade de práticas, de um maior envolvimento do segmento evangélico sobre questôes populares, na tentativa de influenciar as políticas públicas, uma atuação que, de acordo com os fundamentos da Frente Parlamentar Evangélica ${ }^{4}$, busca agir na "defesa da família e da sociedade brasileira", operando através de uma prática legislativa que busque o respeito aos "bons costumes" e à "moralidade".

\section{O PARTIDO SOCIAL CRISTÃO (PSC)}

De acordo com o seu estatuto, o PSC foi criado no dia 15 de maio de 1985 e teve o seu registro definitivo deferido pela Justiça Eleitoral através da resolução do TSE $n^{\circ} 16.357$ de 29/03/1990. No entanto, a história do PSC remonta aos anos setenta, através do político mineiro Pedro Aleixo. Para romper com o bipartidarismo existente durante a ditadura militar, Aleixo resolveu criar o Partido Democrático Republicano (PDR) em setembro de 1970. Apesar de o partido ter conseguido apenas o registro provisório

\footnotetext{
4 A FPE foi oficialmente inaugurada em 18 de setembro de 2003. De acordo com o seu estatuto (2003), no Art. $1^{\circ}$ a FPE representa "[...] uma associação civil, de natureza não-governamental, constituída no âmbito do Congresso Nacional e integrada por Deputados Federais e Senadores da República Federativa do Brasil". Contudo, apesar do caráter suprapartidário da FPE e por agregar parlamentares de diversas denominações evangélicas, a frente não é um organismo coeso, visto que nem todos os deputados evangélicos se identificam com a FPE.
}

Debates do NER, Porto Alegre, Ano I6, N. 27, P. 323-348, JAN./Jun. 2015 
em alguns estados ${ }^{5}$, suas principais lideranças resolveram mudar seu nome em 1985 para Partido Social Cristão, em virtude da doutrina e do posicionamento ideológico dos líderes, principalmente o padre jesuíta José Carlos Brandi Aleixo, filho de Pedro Aleixo. Nesta altura, seriam divulgados o manifesto e estatuto do partido .

De acordo com o seu estatuto, o PSC tem como princípio a Doutrina Social Cristã, em que o Cristianismo representa mais do que uma religião, pois ele é "[...] um estado de espírito que não segrega, não exclui, nem discrimina, mas que aceita a todos, independentemente de credo, cor, raça, ideologia, sexo, condição social, política, econômica ou financeira" (Partido Social Cristão - PSC, 2007, p. 1). Sobre as finalidades do partido, o PSC propõe garantir:

I - o respeito à dignidade da pessoa humana em primeiro lugar, procurando colocá-la acima de quaisquer valores, por mais importantes que eles sejam ou que possam ser;

II - a realização e execução de seu programa com base na Doutrina Social Cristã; III - a disciplina e fidelidade aos princípios programáticos, estatutários, as diretrizes, resoluções e deliberações do PSC aplicáveis a todos os seus filiados, principalmente, no exercício do mandato de cargos e funçōes públicas eletivas ou não;

IV - o poder de definição, assegurado pela Constituição Federal, de sua estrutura interna, organização e funcionamento permanente em âmbito nacional; $\mathrm{V}$ - a defesa e o respeito da soberania nacional, do regime político democrático e do pluripartidarismo;

VI - a defesa e o respeito dos direitos fundamentais da pessoa humana, definidos na Constituição Federal, a ecologia e o meio ambiente;

5 Logo após o momento da publicação do Manifesto, Estatuto e Programa do PDR, em março de 1971, o governo militar decidiu promulgar a Lei ${ }^{\circ}$ 5.682, de 21 de julho, chamada Lei Orgânica dos Partidos Políticos. A lei era repleta de exigências destinadas a impossibilitar o surgimento de um terceiro partido que concorresse com o MDB e a ARENA.

6 Disponível em: <http://psc-bata.blogspot.com.br/2012/08/psc-partido-social-cristao. html>. Acesso em: 8 nov. 2014.

Debates do NER, Porto Alegre, Ano i6, N. 27, P. 323-348, JAN./Jun. 2015 
VII - a participação do PSC nos pleitos eleitorais que se realizarem em todos os níveis, único meio legitimo e pacífico para alcançar o poder e governar com as instituições democraticamente constituídas. (Partido Social Cristão - PSC, 2007, p. 1)

Mesmo com apenas o registro provisório, o PSC participou de todos os processos eleitorais, municipais e gerais em 1989, fazendo também parte da coligação Movimento Brasil Novo, responsável pela eleição de Fernando Collor de Mello.

Logo após o registro definitivo do partido, em 1990, o PSC já angariava os seus primeiros resultados, elegendo Geraldo Bulhões para o governo de Alagoas. Em 1994, o PSC lançou a candidatura do Almirante Hernani Fortuna à Presidência da República, mas o candidato não obteve sucesso e acabou em último lugar. Contudo, cresceram as filiações do partido e consequentemente a legenda alcançou mais visibilidade. Em 1998, o PSC lançou a candidatura de Sérgio Bueno para a Presidência da República. Bueno é Procurador de Justiça e um dos fundadores do partido. O candidato não obteve bom desempenho nas eleições presidenciais e ficou em penúltimo lugar com 0,18\% dos votos válidos. Em 2002, o partido decidiu apoiar a candidatura de Anthony Garotinho no primeiro turno das eleiçôes gerais. Em 2006, o apoio foi dado informalmente ao candidato do PSDC, José Maria Eymael, e, em 2010, o PSC fez parte da coligação Para o Brasil seguir mudando, com a candidata eleita Dilma Rousseff (PT). Atualmente, o PSC possui um senador, deputados federais e estaduais, prefeitos, vice-prefeitos e vereadores em quase todas as Unidades Federativas.

\section{PASTOR EVERALDO DIAS PEREIRA}

Em 2014, foi a vez de Pastor Everaldo entrar em cena como candidato presidenciável. Everaldo Dias Pereira é o atual vice-presidente nacional do PSC. Nasceu em 1956 e é formado em Ciências Atuariais pela Faculdade de Economia e Finanças do Estado do Rio de Janeiro. Entrou no PSC em 2003, sob a influência do então governador do Rio de Janeiro, Anthony Garotinho,

Debates do NER, Porto Alegre, ano I6, N. 27, P. 323-348, JAn./Jun. 2015 
chegando a coordenar programas de governo durante a gestão, sendo subsecretário da Casa Civil. Everaldo possui forte apreço pelos deputados da Frente Parlamentar Evangélica, principalmente pelos assembleianos. Filho de pastor e de missionária, Everaldo morou com a sua família durante a sua infância em uma igreja Assembleia de Deus Ministério Madureira. Ainda jovem, tornou-se pastor da denominação. Em 2000, Everaldo e outros membros da igreja trabalharam para alavancar a candidatura do então governador do Rio de Janeiro, Anthony Garotinho, à Presidência.

No dia 08 de abril de 2014, o PSC lançou Pastor Everaldo como pré-candidato à Presidência da República. O evento, realizado em Brasília, contou com a participação de lideranças políticas e religiosas. Na ocasião, foram citados salmos bíblicos e agradecimentos à Igreja Assembleia de Deus, instituição, segundo Everaldo, responsável por proporcionar os ensinamentos para a sua vida. Durante o lançamento, foi realizada a leitura do programa de governo. Marcondes Gadelha, ex-senador paraibano pelo PSC e coordenador do Programa de Governo de Everaldo, foi o encarregado da exposição. Gadelha dividiu as propostas do PSC em três eixos principais: qualidade de vida, poder nacional e governança ${ }^{7}$.

No ponto relativo à qualidade de vida, são explorados temas como economia livre, empreendedorismo e desenvolvimento econômico, respeito à família assim como à vida humana, que deve ser entendida como tendo início desde a concepção. $\mathrm{O}$ foco privatizante do programa de governo pode ser identificado na seguinte passagem:

Uma economia livre a partir do empreendedorismo individual, com mínima intervenção estatal, priorizando atenção na proteção ao consumidor, gera grande desenvolvimento econômico. Seu estímulo, com redução dos tributos e da burocracia, além do acesso ao crédito, é historicamente a política pública mais eficiente de redução da pobreza. O fim do protecionismo é uma medida urgente, pois é um bloqueio econômico imposto pelo governo contra seus

7 Disponível em: <http://www1.folha.uol.com.br/poder/2014/04/1437787-psc-lanca-precandidatura-de-pastor-everaldo-a-presidencia.shtml>. Acesso em: 8 nov. 2014.

Debates do NER, Porto Alegre, ANo i6, N. 27, P. 323-348, JAN./Jun. 2015 
próprios cidadãos, reduzindo o acesso a bens e serviços, gerando inflação e criando defasagem tecnológica no setor industrial. (Plano de Governo - Partido Social Cristão, 2014, p. 2).

O tom privatizante pode ser verificado em outros pontos explorados no programa, como saúde, agronegócio e educação, em que a ênfase na desburocratização e ampliação do livre-mercado é constante. No ponto relativo à segurança nacional, o partido defende que a reestruturação das polícias e valorização das forças armadas, com maior investimento em capacitação, assim como uma reforma do processo penal, incluindo a redução da maioridade penal, são demandas de todos os brasileiros. O trecho abaixo evidencia a preocupação do PSC sobre o tema.

A segurança pública é uma das áreas de maior apreensão do cidadão brasileiro. Uma legislação penal confusa e excesso de recursos, juntamente com a precarização das polícias, inviabiliza o impedimento do crime, bem como a investigação e julgamento. A execução da pena é feita em presídios condenados por órgãos internacionais de direitos humanos. (Plano de Governo - Partido Social Cristão, 2014, p. 10).

O terceiro eixo, governança, também defende a descentralização, eficiência administrativa e respeito ao direito de propriedade privada. $\mathrm{O}$ programa apresenta como ações que deverão ser empreendidas pelo governo a simplificação dos procedimentos burocratizantes, redução das atribuições do estado e descentralização de poderes e solidez na gestão tributária. $\mathrm{O}$ trecho a seguir demonstra alguns aspectos que representam uma boa governança, segundo o PSC.

A eficiência administrativa só pode ser alcançada com a simplificação e modernização dos trâmites burocráticos; a redução de tributos e competências estatais para que se possa focar na entrega de serviços públicos essenciais; a descentralização administrativa para Estados e Municípios; a criação de metas e incentivos para o setor público; as parcerias público-privadas, o reforço da Lei de Responsabilidade Fiscal para evitar déficits públicos e, principalmente, a

Debates do NER, Porto Alegre, ano I6, N. 27, P. 323-348, JAn./Jun. 2015 
busca de um plano de longo prazo para pagamento da dívida pública, que hoje destrói a possibilidade de investimentos maiores na economia. [...] O respeito ao direito de propriedade privada é outro ponto essencial para uma boa governança, dando ao cidadão o espaço para crescimento individual com redução da dependência estatal. (Plano de Governo - Partido Social Cristão, 2014, p. 12).

Percebe-se que a ênfase na defesa da propriedade privada é constante nas propostas do PSC. Em diversas circunstâncias, como será investigado na próxima seção, o candidato Pastor Everaldo explorou a redução do Estado ao mínimo no seu programa de governo, passando as empresas estatais para a iniciativa privada.

A candidatura de Everaldo estava apoiada neste tripé, basta recordar as inserçóes de mídia e os argumentos utilizados pelo candidato durante as participaçôes nos debates eleitorais presidenciais. Everaldo apresentou um bom desempenho na arrancada da corrida presidencial, prova disso foi a pesquisa eleitoral realizada pelo Datafolha em 06 de junho de 2014, em que o candidato apareceu com $4 \%$ das intenções de voto, situação de empate técnico com o terceiro colocado, Eduardo Campos (PSB), com 7\% das intenções. Contudo, Everaldo não conseguiu manter o desempenho até o final das eleições, muito em virtude da candidatura de Marina Silva (PSB), que assumiu no lugar de Eduardo Campos ${ }^{8}$, e que atraiu um contingente de eleitores evangélicos, inclusive as lideranças da Assembleia de Deus, no momento em que a candidata despontava nas pesquisas eleitorais. Marina Silva representava uma candidatura com potencial real de vitória no segundo turno presidencial. Políticos evangélicos vinculados à Assembleia de Deus, como o deputado federal Marco Feliciano, chegaram a cogitar a possibilidade de desistência de Everaldo no primeiro turno, para evitar uma eventual divisão do voto cristão?.

8 Eduardo Campos faleceu em um acidente de avião no dia 13 de agosto de 2014.

9 Disponível em: <http://www.cpadnews.com.br/universo-cristao/24245/psc-sinaliza -apoio-a-marina-para-eleger-presidente-evangelico.html>. Acesso em: 10 nov. 2014.

Debates do NER, Porto Alegre, Ano i6, N. 27, P. 323-348, JAN./Jun. 2015 
Everaldo não abriu mão da sua candidatura, mesmo com a migração em massa dos seus apoiadores do meio evangélico para Marina Silva. A campanha seguiu pelos estados, com a visita de igrejas evangélicas e outros espaços religiosos. Com relação ao resultado, Pastor Everaldo acabou não sendo eleito, alcançando $0,75 \%$ dos votos válidos, 780.513 votos. Durante o primeiro turno, sua candidatura polarizou com a candidata Luciana Genro (PSOL) em torno de temas como religião, laicidade, aborto, redução da maioridade penal e união homoafetiva. Luciana Genro chegou a afirmar que a vitória sobre Pastor Everaldo já seria uma conquista para as bandeiras que a candidata socialista defende. No segundo turno, o PSC decidiu manifestar apoio ao candidato do PSDB, Aécio Neves.

\section{OS PROGRAMAS ELEITORAIS GRATUITOS DE PASTOR EVERALDO}

Durante a sua campanha eleitoral, o PSC apresentou, através dos programas nacionais de rádio e televisão, suas propostas explorando os principais temas que constituíam as diretrizes programáticas apoiadas nos três eixos do Plano de Governo do partido. Neste artigo, foram coletados e analisados todos os vídeos do Horário Gratuito de Propaganda Eleitoral (HGPE) veiculados pelo PSC durante a campanha do seu candidato presidencial ${ }^{10}$.

A análise discursiva está concentrada na produção de sentidos que emanam dos conjuntos de enunciados que são gerados e identificados nos diversos dizeres fixados nas propagandas eleitorais ${ }^{11}$, como a ênfase na família, a defesa da vida desde a concepção e a política privatizante, estes temas constituirão o corpus da investigação.

${ }^{10}$ O PSC apresentou no total nove propagandas eleitorais durante toda a campanha presidencial. Todos os vídeos apresentados durante o HGPE estavam disponíveis na própria página de Pastor Everaldo na seção Mídia. O período de divulgação dos vídeos foi entre 24/04/2014 e 23/09/2014.

${ }^{11}$ E nos eventuais trechos do Plano de Governo do PSC que são citados nas propagandas durante o HGPE.

Debates do NER, Porto Alegre, ano I6, N. 27, P. 323-348, JAn./Jun. 2015 
Sobre a Teoria do Discurso empregada nesta pesquisa, conforme define Jean-Jacques Courtine (2009), a Análise do Discurso (AD) deve realizar o recorte de um determinado espaço discursivo, o que passa a ser caracterizado como o momento de constituição de um corpus discursivo. A AD produz, no discurso, uma relação do linguístico com o exterior da língua. Courtine defende que "[...] se os processos discursivos constituem a fonte da produção dos efeitos de sentido no discurso, a língua, pensada como uma instância relativamente autônoma é o lugar material onde se realizam os efeitos de sentido" (Courtine, 2009, p. 32). Trata-se de uma tentativa de instituição do discurso como objeto de estudo, privilegiando a percepção da relação entre língua e ideologia. $\mathrm{O}$ surgimento da $\mathrm{AD}$ está caracterizado não só por uma tentativa de estabelecimento de um novo sentido teórico sobre a relação entre o linguístico e o extralinguístico, como também por uma transformação da posição do observador em face do objeto de pesquisa. Entende-se que a linguagem, através de um plano discursivo, não pode apenas reproduzir algo já dado, sendo parte de uma edificação social que rompe com a ficção de naturalidade entre os limites do linguístico e os do extralinguístico. A linguagem não está desagregada da interação social.

Proveniente da Escola Francesa de Análise do Discurso, o conceito de formação discursiva (Foucault, 1997) aplicado neste trabalho servirá para delimitar uma forma de corpus que possui a capacidade de preservar, na análise do discurso político e religioso, a possibilidade de identificar, através das produções e das mudanças discursivas, o efeito inscrito das contradições ideológicas de um determinado grupo social na materialidade dos discursos, servindo para designar os conjuntos de enunciados que estão relacionados a um mesmo sistema de regras, determinadas historicamente (Maingueneau, 1998). As formações discursivas podem ser apreendidas tanto através de uma concepção contrastiva, em que cada formação é refletida como um campo autônomo que colocamos em relação com outros como através de uma concepção interdiscursiva, para a qual uma formação discursiva só poderá se constituir e se manter através do interdiscurso (Ibid.). Percebe-se assim

Debates do NER, Porto Alegre, Ano I6, N. 27, P. 323-348, JAN./Jun. 2015 
que as formações discursivas, a partir das quais emergem os enunciados sobre o sujeito (Foucault, 1997), constituem uma regularidade em meio às dispersões de diversos outros enunciados. É importante destacar que, no método arqueológico foucaultiano de análise do discurso, a investigação percorre o enunciado até a formação discursiva. A regularidade na dispersão apresentada por Foucault, em meio a tudo o que foi verificado sobre o sujeito nos enunciados e nas séries enunciativas presentes no corpus, constitui os diversos dizeres fixados, e também outros que vão se fixando por meio de processos discursivos sobre o sujeito.

Retornando ao tema deste artigo, ou seja, o discurso de Pastor Everaldo nas propagandas eleitorais, a nuvem de termos criada através da transcrição dos vídeos elucida o conteúdo discursivo da candidatura.

Figura 1 - Nuvem de termos identificados no HGPE do candidato Pastor Everaldo (PSC)

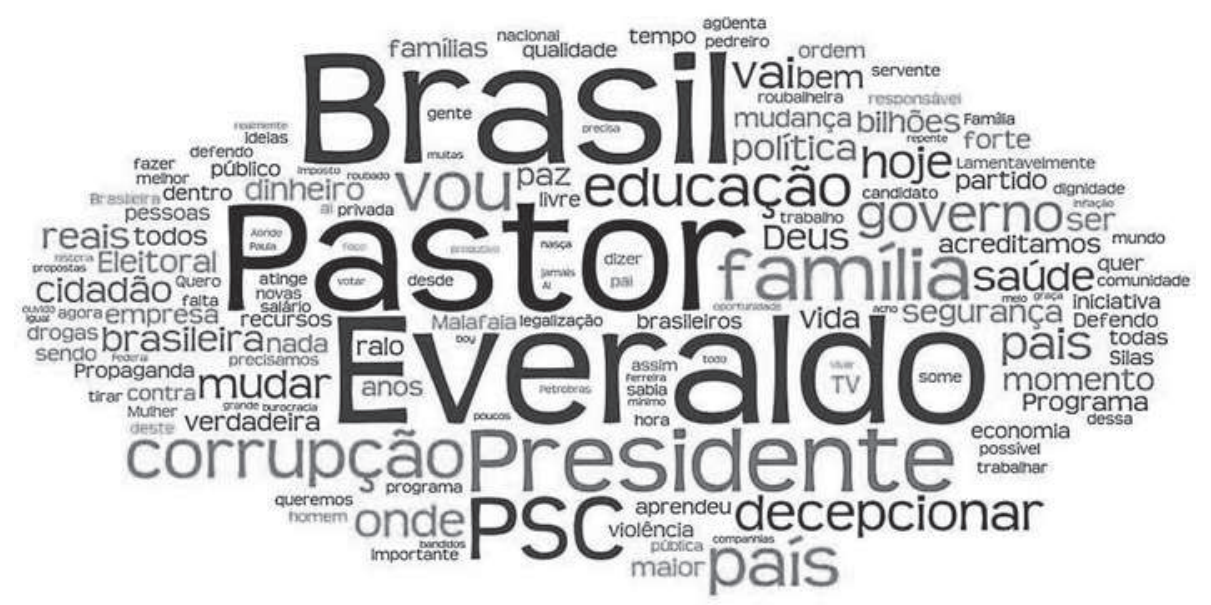

Feito com: <http://www.wordle.net/>. Acesso em: 22 nov. 2014.

Fonte: <http://www.psc.org.br/comunicacao-psc/galeria-de-videos>. Acesso em: 6 nov. 2014

Debates do NER, Porto Alegre, ano I6, N. 27, P. 323-348, JAn./Jun. 2015 
Percebe-se que os termos que ganham destaque nesta visualização são "Pastor", "Everaldo", "Brasil", "Presidente", "PSC”, "família” e "corrupção". Estes constituem os termos mais recorrentes identificados na transcrição dos vídeos. No entanto, isso não quer dizer que cada termo, isoladamente, constituirá um enunciado, ou elemento conector dentro de uma formação discursiva. Os excertos citados a seguir demonstrarão a constituição dos enunciados e a construção dos sentidos proveniente da identificação dos temas mais recorrentes utilizados por Pastor Everaldo nas propagandas eleitorais.

Nós do PSC acreditamos que a família é a base de uma sociedade forte, de um país com ordem e preparado para seguir em frente, acreditamos num caminho onde todos tenham mais oportunidade, onde o setor produtivo seja ouvido e atendido, e você cidadão seja tratado com dignidade e com respeito. Nos últimos anos o Brasil teve um desenvolvimento histórico aproveitando o crescimento da China, Rússia e Índia. Mas hoje o nosso país vai devagar pela burocracia, corrupção e a falta de criatividade econômica. A nossa economia está sem fôlego e o governo não faz nada para mudar isso. $\mathrm{O}$ resultado dessa falta de gerência, falta de comando, é a inflação. O PSC defende um Brasil com menos impostos, maiores investimentos e cooperação com o setor produtivo. É investindo em você, na família, que a gente vai ter um país melhor. (Programa Nacional do PSC - A verdadeira mudança. Disponível em: <https://www. youtube.com/watch?v=xpXvxcI40XM\&list=UUeCpEC2LqVh0IrG6ccsj0w>. Acesso em: 9 nov. 2014.)

Defendo a vida do ser humano desde a sua concepção, sou contra a legalização das drogas, defendo a família como está na Constituição Brasileira. Acredito que um Brasil com famílias fortes será uma nação forte. Sou candidato a Presidente porque igual a você sinto que ninguém aguenta mais esta inversão de valores, onde o cidadão de bem está preso dentro de casa e os bandidos soltos na rua. Quero ser o Presidente para restabelecer a ordem, trazer segurança e paz para cada família do nosso Brasil, o Presidente que vai renovar a esperança e a alegria de viver. (Propaganda Eleitoral Pastor Everaldo na TV - Família (19/08). Disponível em: <http://www.youtube.com/watch?v=Z9hPqDBp 80\&list=UUlHDtWJ0HwBMD6j36C24w9A $>$. Acesso em: 9 nov. 2014.) 
Eu defendo a família como está na Constituição Brasileira. Nós somos um país democrático e respeito todas as pessoas, mas casamento pra mim é homem e mulher. Sou contra a legalização das drogas. Sou contra o aborto. Reafirmo meu compromisso contra a legalização das drogas. Reafirmo meu compromisso com a família como está na Constituição Brasileira. Então eu defendo que o casamento é homem e mulher. Respeito a todas as pessoas. (Programa Eleitoral do Pastor Everaldo na TV. Disponível em: <https://www.youtube. com/watch?v=tIrvMaXIR_E\&list=UUlHDtWJ0HwBMD6j36C24w9A>. Acesso em: 11 nov. 2014.)

Nos trechos citados anteriormente, é constante o argumento de defesa da família brasileira, constituindo assim um ponto nodal ${ }^{12} \mathrm{em}$ quase todos os discursos do candidato sobre o assunto. O discurso de Everaldo exige a atenção sobre as relações entre Estado e religião, visto que é cada vez mais presente a atitude dos atores políticos religiosos de ressignificação do político, de pluralidade de ações, de um maior envolvimento do segmento evangélico sobre as demandas populares, na tentativa de influenciar as políticas públicas, uma atuação que, de acordo com os ensinamentos pentecostais, busca agir na "defesa da família e da sociedade brasileira", operando através de uma prática política que busque o respeito aos "bons costumes" e à "moralidade". O modelo de família preconizado por Everaldo, o qual está na Constituição Brasileira, entende que esta unidade social deve ser formada a partir da união entre homem e mulher, por meio do casamento ou união estável.

\footnotetext{
12 Trata-se de uma categoria desenvolvida por Ernesto Laclau para compreender o estímulo da prática discursiva através de um ponto capaz de articular as mais diversas demandas diante de uma fronteira antagônica instável. O ponto nodal, ou aquele momento do discurso que é capaz de aglutinar, é proveniente da psicanálise lacaniana. Laclau parte desta referência e chama de pontos nodais aqueles pontos discursivos privilegiados dentro de uma fixação parcial de sentido, mesmo que estes apresentem ainda todo um caráter de contingência e precariedade (Laclau; Mouffe, 1987). Esses pontos discursivos resultam de um momento de oposição a algo que é percebido como inimigo, ou seja, aquilo que de fato representa uma ameaça, situação na qual surge uma relação antagônica.
}

Debates do NER, Porto Alegre, ano I6, N. 27, P. 323-348, JAn./Jun. 2015 
A postura de Everaldo é criticada por membros da comunidade LGBT, que caracterizam o candidato como fundamentalista e conservador sobre temas que dizem respeito à luta do segmento LGBT pelos direitos já adquiridos, deslegitimando qualquer modelo de família que não se encaixe nos padrões heteronormativos que são impostos pelos evangélicos.

Outro ponto exaustivamente citado por Everaldo durante a sua campanha foi a defesa da vida desde a concepção. Em diversas circunstâncias, o candidato evangélico demonstrou sua postura contrária ao aborto, apresentando nas propagandas eleitorais imagens de gestantes ao mesmo tempo em que reafirmava a defesa da família associada também à contrariedade da interrupção da gravidez.

Mas não somente em torno de temas que remetem a um conservadorismo moral são construídos os discursos de Pastor Everaldo. Em várias ocasiōes o candidato do PSC defendeu a iniciativa privada e a redução da máquina pública ao mínimo, associando o seu discurso também a uma espécie de conservadorismo de ordem econômica. Os seguintes trechos evidenciam a preocupação do candidato acerca do tema:

Quero ser o Presidente para restabelecer a ordem, trazer segurança e paz para cada família do nosso Brasil, o Presidente que vai renovar a esperança e a alegria de viver. Vou cortar na carne, reduzir a máquina do Estado ao mínimo necessário, e passarei tudo o que for possível para a iniciativa privada. O foco do meu governo será servir ao cidadão. Eu não vou decepcionar você, eu não vou decepcionar o Brasil. (Propaganda Eleitoral Pastor Everaldo na TV - Família (19/08). Disponível em: <http://www.youtube.com/watch? $\mathrm{v}=\mathrm{Z} 9 \mathrm{hPqDBp} 80 \&$ list $=\mathrm{UU}$ HHDtWJ0HwBMD6j36C24w9A $>$. Acesso em: 9 nov. 2014.)

Vou acabar com a burocracia do atual Governo. Reduzirei o tamanhão da máquina pública para o mínimo necessário. Atualmente o Brasil tem mais de cem empresas estatais, muitas com corrupção e perdas bilionárias. Só a Petrobras tem uma dívida de mais de 200 bilhões de reais. Defendo o livre mercado, a livre concorrência. Se Deus quiser, eleito presidente o trabalhador 
que recebe um salário de até 5 mil reais por mês, ficará isento do imposto de renda na fonte. (Pastor Everaldo - Programa de Economia. Disponível em: $<$ http://www.youtube.com/watch?v=91a6zTIZPDA\&list=UUlHDtWJ0H wBMD6j36C24w9A>. Acesso em: 10 nov. 2014.)

Defendo a livre iniciativa e a livre concorrência, por isso vou passar todas as empresas que hoje são foco de negócios políticos e corrupção para iniciativa privada. O imposto que você paga que some no ralo da corrupção, será aplicado na saúde, na educação e na segurança pública. Eu não vou decepcionar você, eu não vou decepcionar o Brasil. (Programa Eleitoral do Pastor Everaldo na TV - Minha Vida. Disponível em: <http://www.youtube.com/ watch?v=36_JpiwaXm4\&list=UUlHDtWJ0HwBMD6j36C24w9A >. Acesso em: 11 nov. 2014.)

Sobre os evangélicos na política, segundo Antônio Flávio Pierucci (1989), a postura conservadora na esfera cultural e fundamentalista na esfera religiosa, alinhada com os grupos conservadores sobre questões de ordem socioeconômica, já era identificada na Constituinte. De acordo com o seu artigo intitulado Representantes de Deus em Brasilia: a bancada evangélica na Constituinte (1989), Pierucci já identificava a bem-sucedida mobilização eleitoral de setores do protestantismo conservador, apresentando-se como uma alternativa política para os demais membros de suas igrejas e seus líderes. Ao analisar a atuação desse grupo conservador no Congresso, Pierucci argumenta que esse se constitui como uma "nova direita", por estar atenta aos temas de ordem conservadora moral e econômica, no entanto, ao mesmo tempo em que este identifica um caráter conservador demonstra também a sua origem popular. Não foram poucas as ocasiōes nas quais Everaldo também explorou a sua origem humilde. Desde criança, trabalhou como camelô na feira e servente de pedreiro. Posteriormente, realizou a defesa da iniciativa privada e do livre mercado.

Apesar desta exploração, pelos evangélicos, de temas de cunho conservador moral e econômico ser identificada desde a Assembleia Constituinte, foi a primeira vez que uma candidatura evangélica para Presidente da

Debates do NER, Porto Alegre, ano I6, N. 27, P. 323-348, JAn./Jun. 2015 
República utilizou destas matérias para o programa político. A defesa da família e da vida desde a concepção, temas de natureza moral, assim como a ênfase na iniciativa privada, tema de natureza econômica, constituem os elementos, ou enunciados, situados dentro de uma relação interdiscursiva, responsável pela constituição das formações discursivas de caráter conservador, e esta foi a principal característica do discurso de Pastor Everaldo durante a sua campanha eleitoral, ou seja, a convergência de duas espécies de conservadorismo.

\section{CONSIDERAÇÕES FINAIS}

Com relação ao envolvimento dos evangélicos na política institucional brasileira, as eleições de 2014 apresentaram um novo quadro. O nome de Pastor Everaldo para Presidente da República demonstrou que os evangélicos estão garantindo força na esfera política, e não estão mais concentrados apenas nos espaços legislativos de atuação. Trata-se de um candidato que explorou desde o início da campanha a sua identidade religiosa, sua origem familiar vinculada a uma das maiores igrejas pentecostais do Brasil, a Assembleia de Deus e a defesa de temas conservadores.

Apesar de não ser a primeira candidatura para um cargo majoritário que explora a orientação religiosa durante a campanha, o candidato do PSC, assim como o seu projeto político e consequentemente a sua trajetória, contribuíram para apresentar o que pode ser caracterizado como um novo modelo de político evangélico. O discurso de Everaldo demonstrou que não basta apenas para um candidato de orientação evangélica continuar defendendo as antigas bandeiras da preservação da moralidade privada tradicional, baseada em discursos bíblicos proselitistas. Obviamente que ainda é perceptível um ativismo político conservador centrado em questões de natureza moral, alicerçada em preceitos confessionais que recorrem ao simbolismo explorado pelos evangélicos nas suas denominações em torno de temas como: família, sexo e defesa da vida. No entanto, esta preocupação 
começa a dividir espaço com outra, a ênfase em um conservadorismo de ordem econômica. A candidatura de Pastor Everaldo não poupou frases no decorrer da campanha justificando que a burocracia dos últimos governos e a má gestão das empresas estatais gera mais corrupção. A solução para o candidato é a redução da máquina pública para o mínimo necessário. Defendendo a livre iniciativa e a livre concorrência, seu programa de governo propóe a privatização das empresas públicas, que, de acordo com Everaldo, são foco de negócios políticos e corrupção, como a Petrobras.

A associação entre estas duas espécies de conservadorismo nunca ganhou tanta ênfase em uma corrida presidencial, sobretudo por um candidato de orientação pentecostal. A imbricação entre discursos voltados para a defesa da família, da vida desde a concepção, da iniciativa privada e da redução do Estado formaram o pano de fundo programático da candidatura de Everaldo. O material empírico investigado neste artigo evidenciou esta preocupação, assim como abriu a possibilidade de uma melhor visualização do eleitorado evangélico em virtude das manifestações de apoio ao candidato Pastor Everaldo, e depois, também a Marina Silva, em alguns meios de comunicação evangélicos, manifestos públicos e nos cultos das principais igrejas pentecostais do país.

Com o crescimento numérico dos evangélicos no Brasil, surge também a expansão deste segmento nos canais políticos de atuação. $\mathrm{O}$ abandono da postura sectária e avessa à participação política e à ênfase na função parlamentar em defesa da vida, da família e da liberdade religiosa são sinais destas transformações que ocorrem no âmago das igrejas pentecostais e neopentecostais. A candidatura de Pastor Everaldo, apesar da evaporação dos votos no decorrer do primeiro turno, demonstra um novo panorama, ou seja, mesmo com a falta de coesão em torno dos interesses dos políticos evangélicos e das suas principais lideranças, surge a necessidade de uma candidatura majoritária que seja capaz de representar totalmente esse segmento nas eleições presidenciais vindouras.

Debates do NER, Porto Alegre, ano I6, N. 27, P. 323-348, JAn./Jun. 2015 


\section{REFERENCIAS}

CAMPOS, Leonildo S. De políticos de Cristo: uma análise do comportamento político de protestantes históricos e pentecostais no Brasil. In: BURITY, Joanildo; MACHADO, Maria das Dores. (Org.). Os Votos de Deus: evangélicos, política e eleições no Brasil. Recife: Fundação Joaquim Nabuco, Ed. Massangana, 2006. p. 29-89.

COURTINE, Jean-Jacques. Análise do discurso político: o discurso comunista endereçado aos cristãos. São Paulo: EdUFSCar, 2009.

FOUCAULT, Michel. A arqueologia do saber. 5. ed. Rio de Janeiro: Forense Universitária, 1997.

FRESTON, Paul. Protestantes e política no Brasil: Da Constituinte ao Impeachment. 1993. Tese (Doutorado em Ciências Sociais)-Instituto de Filosofia e Ciências Humanas, Universidade Estadual de Campinas, Campinas, 1993.

LACLAU, Ernesto; MOUFFE, Chantal. Hegemonía y estrategia socialista: hacia una radicalización de la democracia. Madrid: Siglo XXI, 1987.

MAINGUENEAU, Dominique. Termos-chave da análise do discurso. Belo Horizonte: Ed. UFMG, 1998.

MARIANO, Ricardo. Pentecostais e política no Brasil: do apolitismo ao ativismo corporativista. In: SANTOS, Hermílio. (Org.). Debates pertinentes: para entender a sociedade contemporânea. 1. ed. v. 1. Porto Alegre: EdiPUCRS, 2010. p. 101-124.

NOVAES, Regina. Crenças religiosas e convicções políticas: fronteiras e passagens. In: FRIDMAN, Luis Carlos. (Org.). Política e Cultura: século XXI. Rio de Janeiro: Relume Dumará, ALERJ, 2002. p. 63-98.

ORO, Ari Pedro. Religião e Política no Brasil. In: ORO, Ari Pedro (Org.). Religião e Politica no Cone-sul, Argentina, Brasil e Uruguai. São Paulo: Attar Editorial, 2006. p. 75-156.

Debates do NER, Porto Alegre, Ano I6, N. 27, P. 323-348, JAN./Jun. 2015 
PARTIDO SOCIAL CRISTÃO - PSC. Histórico. Disponível em: <http://pscbata.blogspot.com.br/2012/08/psc-partido-social-cristao.html>. Acesso em: 8 nov. 2014.

. Plano de Governo. Eleições 2014. Disponível em: <http://divulgacand2014.tse.jus.br/divulga-cand 2014/>. Acesso em: 5 nov. 2014.

. Estatuto. Resolução/TSE no 22.649, de 27.11.2007, publicada no Diário da Justiça em 17.12.2007.

PASTOR Everaldo - Programa de Economia. Disponível em: <http:// www. youtube. $.0 m /$ watch? $=91$ a6zTIZPDA\&list=UUlHDtWJ0HwBMD6j36C24w9A>. Acesso em: 9 nov. 2014.

PIERUCCI, Antônio Flávio. Representantes de Deus em Brasília: A Bancada Evangélica na Constituinte. Ciências Sociais Hoje, São Paulo, n. 11, p.104$132,1989$.

PIERUCCI, Antônio Flávio; MARIANO, Ricardo. O envolvimento dos pentecostais na eleição de Collor. Novos Estudos Cebrap, São Paulo, n. 34, p. 92-106, nov. 1992.

PROGRAMA Eleitoral do Pastor Everaldo na TV. Disponível em: <https:// www.youtube.com/watch?v=tIrvMaXIR_E\&list=UUlHDtWJ0HwBMD6j36C24w9A>. Acesso em: 10 nov. 2014.

PROGRAMA Eleitoral do Pastor Everaldo na TV - Minha Vida. Disponível em: <http://www.youtube.com/watch?v=36_JpiwaXm4\&list=UUlHDtWJ0HwBMD6j36C24w9A>. Acesso em: 8 nov. 2014.

PROGRAMA Nacional do PSC - A verdadeira mudança. Disponível em: <https://www.youtube.com/watch? $\mathrm{v}=x \mathrm{X}$ XvxcI40XM\&list=UUeCpEC2 LqVh0IrG6ccsj0w>. Acesso em: 10 nov. 2014.

PROPAGANDA Eleitoral Pastor Everaldo na TV - Família (19/08). Disponível em: <http://www.youtube.com/watch?v=Z9hPqDBp80\&list=UUlHDtWJ0HwBMD6j36C24w9A>. Acesso em: 9 nov. 2014.

Debates do NER, Porto Alegre, ano I6, N. 27, P. 323-348, JAn./Jun. 2015 
PSC LANÇA pré-candidatura de Pastor Everaldo a presidência. Folha de São Paulo, São Paulo. Disponível em: <http://www1.folha.uol.com.br/ poder/2014/04/1437787-psc-lanca-pre-candidatura-de-pastor-everaldoa-presidencia.shtml>. Acesso em: 8 nov. 2014.

PSC SINALIZA apoio a Marina para eleger presidente evangélico. CPAD News. Disponível em: <http:/www.cpadnews.com.br/universo-cristao/24245/ psc-sinaliza-apoio-a-marina-para-eleger-presidente-evangelico.html>. Acesso em: 10 nov. 2014.

Recebido em: 10/01/2015

Aprovado em: 02/03/2015 